\title{
Sensory and Physiochemical Comparison of Traditional Bone-In Dry-Aged Beef Loin with Bone-Less Dry Ageing and Ageing Using a Moisture Permeable Bag
}

\author{
Maurice G. O’Sullivan1*, Malco C. Cruz-Romero², Joseph P. Kerry ${ }^{2 *}$ \\ ${ }^{1}$ Sensory Group, School of Foodand Nutritional Sciences, University College Cork, Cork, Ireland \\ ${ }^{2}$ Packaging Group, School of Foodand Nutritional Sciences, University College Cork, Cork, Ireland \\ Email: *maurice.osullivan@ucc.ie, *Joe.Kerry@ucc.ie
}

How to cite this paper: O'Sullivan, M.G., Cruz-Romero, M.C. and Kerry, J,P. (2018) Sensory and Physiochemical Comparison of Traditional Bone-In Dry-Aged Beef Loin with Bone-Less Dry Ageing and Ageing Using a Moisture Permeable Bag. Food and Nutrition Sciences, 9, 1078-1098. https://doi.org/10.4236/fns.2018.99079

Received: July 17, 2018

Accepted: September 16, 2018

Published: September 19, 2018

Copyright $\odot 2018$ by authors and Scientific Research Publishing Inc. This work is licensed under the Creative Commons Attribution International License (CC BY 4.0).

http://creativecommons.org/licenses/by/4.0/

\begin{abstract}
Beef loins, were de-boned and left unpackaged $(\mathrm{n}=12)$ or packaged using dry-ageing bags $(\mathrm{n}=12)$. A third batch $(\mathrm{n}=12)$ were not boned out and unpackaged. Loins were aged in a chill at $2^{\circ} \mathrm{C}$, with steaks $(2.54 \mathrm{~cm})$ tested on days $0,7,14$ and 21 for \% yield, colour, texture, $\mathrm{pH}$, cooking losses and microbiological status. Sensory affective analysis and a novel descriptive method (Ranking Descriptive Analysis) were also performed. The dry aged samples had significantly $(\mathrm{P}<0.05)$ higher moisture losses followed by dry-ageing bag samples and bone-in samples. The bone-in samples scored lower for appearance at 21 days, were juicier, but had more off-flavour. Dry aged beef scored significantly higher than the bone-in samples for overall acceptability, but were not significantly better than the dry-ageing bag samples which had reduced moisture losses and greater tenderness. Microbiologically all treatments performed similarly. There were no significant differences in trim losses between dry-aged samples with or without the use of ageing bags. The sensory methods utilised allowed samples to be assessed hedonically and descriptively in real time without the necessity to freeze samples and without reverse storage design.
\end{abstract}

\section{Keywords}

Sirloin, Tenderloin, Beef, Dry-Aged, Package, Sensory, Affective, Novel, Rapid, Descriptive, Texture

\section{Introduction}

Fresh beef products often are aged to enhance palatability characteristics associ- 
ated with various retail and wholesale cuts [1]. Aging involves storing the meat at refrigerated temperatures for usually 21 days or more which in turn optimises the palatability characteristics of the meats such as tenderness, juiciness, and flavour [2] [3] [4]. There are two methods of aging: wet aging, the most common, is storing beef cuts in vacuum packages and dry aging refers to storing beef carcasses or wholesale cuts without any type of protective packaging [1]. Wet-ageing is the aging method used by about $95 \%$ of US producers of beef products [4]. Traditional dry aging exposes unpackaged meat directly to cooler conditions with strict temperature, humidity, and air-flow control [5]. Dry aging is a more costly procedure that requires a significant amount of time and space, elicits a high amount of shrink, and generates a significant amount of excess dried waste-termed in the industry as "crust"-that must be trimmed [1]. However, the increased sensory quality of dry aged beef compared to wet aged allows this product to be sold at a higher premium. Dry-aging is employed as producers believe it enhances overall palatability while creating a premium price for beef products [6]. Wet-aged beef has a sour and strong bloody/serumy flavour, whereas dry-aged beef has a beefy, brown roasted flavour that is considered desirable [4]. Assessors are more familiar with wet- than dry-aged flavours, but when assessors recognized or preferred the dry-aged flavour profile, they were willing to pay more for this product [1] [7] [8] [9]. Also, aging of fresh beef for retail and foodservice has become essential to meet the high demands and expectations of an exceptional eating experience [7]. Dry-aging has been a successful process used by some high-end restaurants and specialty outlets to meet the needs of assessors who prefer this unique product [1]. Foodservice has capitalized on the perceived value of dry-aged beef products and has been able to merchandise these products at premium prices [7].

If aging could occur in a highly moisture-permeable bag, however, it may be possible to "dry-age" beef in a package and have it be more tolerant to more variable cooler conditions. Such methodology could potentially decrease trim loss and microbial contamination, thus maximizing yields [5]. Previously researchers [5] found that dry aging of beef in a highly moisture-permeable bag was feasible, positively impacted on yields and reduced microbial spoilage, with no negative impact on product quality. Additionally, some researchers [9] have found that leaving the bone on the beef loin during ageing decreased the amount of flavour development, perhaps by limiting the loss of moisture during aging and the resultant "concentration" of flavour components [9].

Much of the research conducted comparing wet and dry aged beef has been undertaken using assessors ([1] $\mathrm{n}=77,[7] \mathrm{n}=80$ - 91) and the research comparing these ageing regimes to those incorporating moisture permeable bags and bone-in samples have used trained panellists [9] $n=6$; [10], $n=6$. Sensory Acceptance Testing is a hedonic sensory methods used to determine the degree to which products are liked and has been applied to various product including meats [11]-[17], dairy products [18]-[29], salads, [30] [31], Bakery products [32] [33] and beverages [34] [35] [36] [37] [38]. Thus the objective of the present 
study was to directly compare the sensory acceptability, using sensory acceptance testing, of traditional bone-in dry aging to de-boned dry aged loins and de-boned dry aged loins in moisture permeable bags (dry-ageing bag), in the same study. Additionally, a flash profiling descriptive analysis technique [39]-[46] called Ranking Descriptive Analysis [47]-[52] was performed as well as \% yield, microbial and physiochemical changes after 0, 7, 14 and 21 days at $2{ }^{\circ} \mathrm{C}$. Previous studies have used meat from frozen beef. All samples tested in the present study were unfrozen and tested in real time at the experimental time points as freezing is not a process step usually utilised for dry ageing of beef in the meat industry because of potential deleterious effects on quality. A more sophisticated approach of undertaking descriptive analysis, without the necessity of freezing, and to prevent assessor bias is to incorporate reverse storage design. Reversed storage design can be performed by staggering product times, so that all products with different storage times are evaluated on the same day [53]. Byrne, O'Sullivan, Bredie and Martens [54] undertook a similar strategy in a descriptive sensory profiling test of warmed-over flavour in meat patties. However reverse storage design does not lend itself easily for routine sensory quality monitoring programmes. Thus, the strategy employed in the presented study displays a real time sensory monitoring system to assess sensory attributes (hedonic and descriptive) without the necessity of freezing samples and without the complexity and difficulty of employing reverse storage design.

\section{Materials and Methods}

\subsection{Meat Samples, Packaging and Storage}

18 Beef heifers (Hereford Crosses), aged 17 - 20 months, were slaughtered at a local abattoir on the same day according to EU Council Directive 93/119/EC. The carcasses used in this study originated from animals which were grass pasture fed in the absence of concentrates, as it is standard practice in Ireland during Spring/Summer/Autumn period. Muscles were removed from carcasses 0 days post-mortem. One set of primal beef cuts $(n=12)$, containing the top sirloin and tenderloin muscles as defined by standard Irish and UK butchering practices, were fully de-boned and packaged in the factory using the permeable dry-ageing bags (Tublin ${ }^{\oplus} 88$ 10, TUB-EX ApS, Denmark). The bags were composed of $50 \mu \mathrm{m}$ thick polyamide mix (water vapour transmission rate $5000 \mathrm{~g} / 50 \mu / \mathrm{m} 290 / 24 \mathrm{~h}$ at $38^{\circ} \mathrm{C}$ and $50 \%$ relative humidity). The second batch of primal beef cuts were also de-boned, but left unpackaged. The third batch of samples were not boned out and left unpackaged. All samples were placed intact on wire mesh shelving in to a chill room at $2^{\circ} \mathrm{C}$ and 3 sets of samples from each treatment were sacrificed on nominated test days (D0, D7, D14 and D21) for all analyses throughout storage. All primals were cut in to 1 inch $(2.54 \mathrm{~cm})$ prior to analysis.

\subsection{Instrumental Texture Analysis-Warner-Bratzler Shear Force}

Two steaks of 1 inch thickness were prepared from the dry aged beef dry-ageing 
bag aged beef and bone in aged beef after storage at $2^{\circ} \mathrm{C}$ for D0, D7, D14 and D21 days for tenderness analysis. These steaks were cut at 90 degrees to the length of the muscle fibres, wrapped in aluminium foil and cooked in an electric forced convection oven, which was preheated to $200^{\circ} \mathrm{C}$, to a core temperature of $70^{\circ} \mathrm{C}$. The core temperature was monitored using a Testo 110 with type NTC probe (Testo Ltd., UK). After cooking, steaks for shear force determination were stored in a cooler at $2^{\circ} \mathrm{C}$ overnight before coring. At least twelve $1.27 \mathrm{~cm}$ diameter cores from each steak were removed parallel to the longitudinal orientation of the muscle fibres. The cores were sheared perpendicular to the muscle fibres orientation using a Texture Analyser TA-XT2i (Stable Micro Systems, UK) with a Warner-Bratzler shear device and crosshead speed set at $3 \mathrm{~mm} / \mathrm{s}$. The considered parameter was the maximum shear force in Newtons. Results were expressed as the mean shear force value \pm standard deviation.

\subsection{Instrumental Measurement of Colour}

The surface colour of beef steaks was measured according to the CIE $\mathrm{L} \times \mathrm{a} \times \mathrm{b} \times$ colour system using a Minolta CR 300 colorimeter (Minolta Camera Co. Ltd., Osaka, Japan). The chroma meter was calibrated on the Hunterlab colour space system using a white ceramic tile (C: $Y=93.6, x=0.3130, y=0.3193$ ), (Minolta calibration plate). Six readings were taken per sample on each measurement day at each time point of retail display.

\subsection{Measurement of Muscle $\mathrm{pH}$}

The $\mathrm{pH}$ of the muscle was recorded using a portable $\mathrm{pH}$ meter (Mettler Toledo, MP 125, Switzerland). The $\mathrm{pH}$ of the beef steaks was taken by making a small scalpel incision in the muscle and inserting a glass electrode approximately $1 \mathrm{~cm}$ into the muscle. A total of three readings were taken per each steak and averaged for statistical analysis.

\subsection{Microbiological Analysis}

Microbiological analyses of beef joints stored under different packaging (Aerobic, and Dry-ageing bag) conditions at $2^{\circ} \mathrm{C}$ were performed in triplicate on each measurement day. In order to obtain a representative sample, a number of subsamples were taken aseptically using sterile forceps and scalpels from different parts of the carcass into a sterile stomacher bag, pooled and thoroughly mixed and $10 \mathrm{~g}$ of the pooled meat samples were weighted aseptically into a stomacher bag in a vertical laminar-flow cabinet and a primary 10 -fold dilution was performed by addition $(90 \mathrm{ml})$ of sterile maximum recovery diluent (Oxoid, Basingstoke, U.K.). Following homogenisation in a stomacher for $3 \mathrm{~min}$, homogenates were serially diluted 10 -fold in maximum recovery diluent solution, and $1 \mathrm{ml}$ of each appropriate dilution was inoculated on duplicated plates in the centre of compact dry-total count plates $\left(20 \mathrm{~cm}^{2}\right.$ ) (Nissui Pharmaceutical, Co. Ltd., Japan) for enumeration of total mesophilic aerobic bacteria following in- 
cubation at $37^{\circ} \mathrm{C}$ for 48 hours.

Total coliforms and E. coli were enumerated on Brilliance E. Coli/Coliform Selective Agar (Oxoid) following incubation at $37^{\circ} \mathrm{C}$ for $24 \mathrm{hr}$. Oxoid Brilliance E. coli/coliform Selective Agar is a chromogenic medium for the detection and enumeration of E. coli and other coliforms (important hygiene indicators) from food. Chromogenic agents within the medium are used to detect the $\beta$-glucuronidase activity of $E$. coli and the $\beta$-galactosidase activity of coliforms (including $E$. coli), allowing them to be clearly differentiated on the culture plate (coliforms-pink, E. coli-purple).

\subsection{Sensory Evaluation}

The sensory acceptance test was conducted using untrained assessors $(\mathrm{n}=27$ 33) [55] [56] who were regular consumers of beef steak products and had previously consumed and were familiar with dry-aged beef. Assessors assesed the samples presented to them on days 0 (Assessors $n=30), 7(n=33), 14(n=30)$ and $21(\mathrm{n}=27)$ days. Two steaks of 1 inch thickness were prepared from three separate samples of dry aged beef, packaged dry-aged beef (dry-age bag) and bone in aged beef after storage at $2^{\circ} \mathrm{C}$ for D0, D7, D14 and D21. These steaks were cut at 90 degrees to the length of the muscle fibres, wrapped in aluminium foil and cooked in an electric forced convection oven, which was preheated to $180^{\circ} \mathrm{C}$, to a core temperature of $70^{\circ} \mathrm{C}$. The core temperature was monitored us-

ing a Testo 110 with type NTC probe (Testo Ltd, UK). The outer surface of meat samples was trimmed prior to sensory analysis. After cooking, Steaks were cut into $2 \mathrm{~cm} \times 2 \mathrm{~cm}$ cubes and identified with a three digit codes before immediate serving of the samples to the assessors. The serving order was randomised for each assessor. Assessors were provided with water to cleanse their pallets between samples. The assessors were asked to evaluate the following hedonic descriptors: liking of appearance, liking of flavour and overall acceptability. Additionally the assessors were asked to assess juiciness, tenderness as well as off flavour using ranking descriptive analysis (RDA) [57], a method that can be used for concise focussed descriptive analysis using either trained or untrained assessors. All samples were again presented in duplicate [58]. Samples were also presented coded and randomised. Assessors were also asked to rank steaks according to their preference using the descriptors Unsatisfactory, Good, Very Good and Excellent every day eating quality. The experiment was conducted in panel booths which conform to the International Standards [59].

\subsection{Percentage Yield}

All intact treatment samples were initially weighed on Day 0 of analysis and then relevant samples returned to the chill at $2^{\circ} \mathrm{C}$. On D7, D14 and D21 sample treatments were re-weighed and the loss in weight was expressed as weight loss $[(\mathrm{kg}) /$ initial weight $(\mathrm{kg})] \times 100$. Trim loss was calculated as the weight of loins after trimming in the factory divided by the weight of samples at Day $21 \times 100$, 
in the case of samples using ageing bags, these were removed prior to weighing.

\subsection{Data Analysis}

ANOVA-Partial Least Squares Regression (APLSR) [52] was used to process the raw data accumulated from the +30 test subjects during the sensory evaluation and physiochemical analysis. The $\mathrm{X}$-matrix was designed as $0 / 1$ design variables for treatment and days of retail display. The Y-matrix was designed as sensory, chemical and instrumental variables. The optimal number of components in the APLSR models presented was determined to be 4 Principal Components (Figure 1). PC 3 versus PC 1 is presented; the other PC's did not yield additional information or provide any predictive improvement in the Y-matrix obtained through their examination. The validated explained variance for the model constructed was $34 \%$. And the calibrated variance was $31 \%$. To derive significance indicators for the relationships determined in the quantitative APLSR, regression coefficients were analyzed by jack-knifing (Table 2) which is based on cross-validation and stability plots [60] [61]. All analyses were performed using the Unscrambler Software, version 9.7 (CAMO ASA, Trondheim, Norway). Table 1(b) presents P-Values from the estimated regression coefficients for the ANOVA-Partial Least Squares Regression (APLSR). Significant P-Values in are in BOLD. The Sign dictates weather the correlation is positively or negatively correlated. Values correspond to mean data, \pm corresponds to standard deviation.

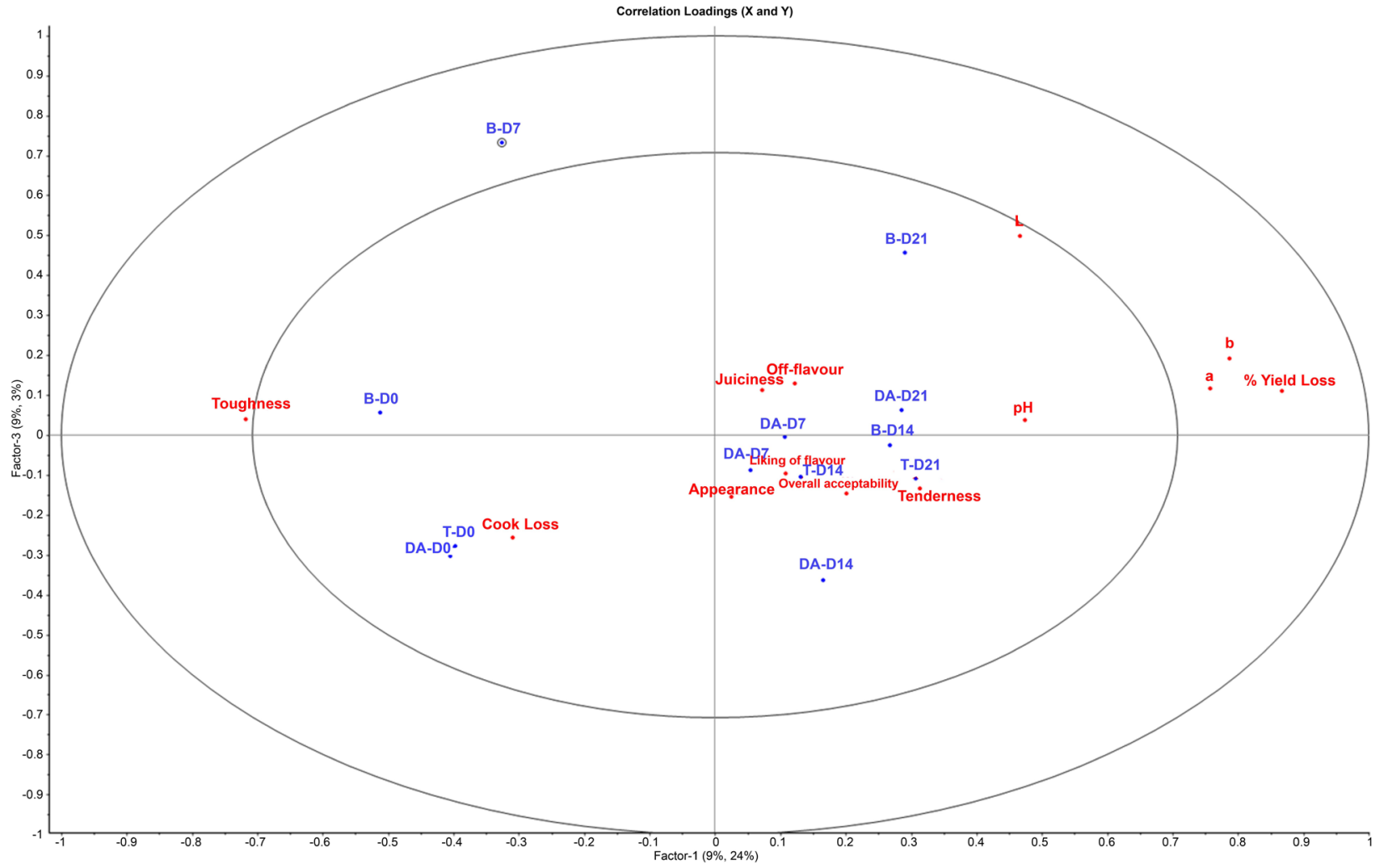

Figure 1. Anova-partial least squares regression plot of the raw sensory data for dry aged, dry-ageing bagaged and bone-in aged striploin steaks after $0,7,14$ and 21 days storage at $2^{\circ} \mathrm{C}$. PC 1 vs PC 2 presented. 
Table 1. Significance of estimated regression coefficients (P values) for the relationships of sensory terms as derived by Jack-knife uncertainty testing for beef steak samples presented with mean sensory data and standard deviations.

\begin{tabular}{|c|c|c|c|c|c|c|c|c|c|c|c|c|c|c|c|c|c|c|}
\hline \multirow[t]{2}{*}{ Code } & \multicolumn{6}{|c|}{ Appearance Liking of flavour } & \multicolumn{3}{|c|}{ Overall acceptability } & \multicolumn{3}{|c|}{ Juiciness } & \multicolumn{3}{|c|}{ Tenderness } & \multicolumn{3}{|c|}{ Off-Flavour } \\
\hline & Mean & SD & $\begin{array}{c}\mathbf{P} \\
\text { Value }\end{array}$ & Mean & SD & $\begin{array}{c}P \\
\text { Value }\end{array}$ & Mean & SD & P Value & Mean & SD & $\begin{array}{c}P \\
\text { Value }\end{array}$ & Mean & SD & $\begin{array}{c}\mathbf{P} \\
\text { Value }\end{array}$ & Mean & SD & $P$ Value \\
\hline $\mathrm{DA}-0$ & 6.66 & 1.68 & -0.111 & 5.99 & 1.44 & -0.854 & 5.76 & 1.26 & -0.417 & 5.00 & 1.64 & -0.904 & 4.75 & 2.02 & -0.029 & 0.44 & 0.65 & -0.005 \\
\hline DA-7 & 5.71 & 1.42 & 0.110 & 6.13 & 1.36 & 0.368 & 5.79 & 1.31 & 0.517 & 4.19 & 1.77 & 0.003 & 5.22 & 1.35 & 0.831 & 0.68 & 0.92 & 0.865 \\
\hline DA-14 & 6.58 & 1.37 & 0.183 & 6.29 & 1.53 & 0.127 & 6.51 & 1.39 & 0.085 & 5.09 & 1.90 & 0.692 & 6.14 & 1.32 & 0.048 & 0.63 & 0.92 & 0.595 \\
\hline DA-21 & 6.76 & 1.50 & 0.524 & 6.26 & 1.21 & 0.208 & 6.52 & 1.41 & 0.174 & 5.39 & 1.59 & 0.043 & 5.51 & 1.69 & 0.073 & 0.55 & 0.67 & 0.102 \\
\hline T-0 & 6.75 & 1.74 & -0.107 & 6.17 & 1.54 & -0.911 & 5.53 & 1.66 & -0.461 & 5.15 & 2.13 & 0.418 & 4.35 & 2.20 & -0.041 & 0.38 & 0.82 & -0.020 \\
\hline T-7 & 6.16 & 1.00 & 0.105 & 5.79 & 1.47 & 0.466 & 5.63 & 1.13 & 0.604 & 3.81 & 1.40 & 0.001 & 5.30 & 1.53 & 0.819 & 0.65 & 0.79 & 0.666 \\
\hline $\mathrm{T}-14$ & 6.64 & 1.68 & 0.869 & 5.70 & 1.61 & 0.848 & 6.23 & 1.63 & 0.666 & 5.00 & 1.87 & 0.185 & 5.72 & 1.74 & 0.410 & 0.93 & 1.21 & 0.907 \\
\hline $\mathrm{T}-21$ & 7.01 & 1.46 & 0.568 & 6.26 & 1.29 & 0.176 & 6.06 & 1.47 & 0.072 & 4.57 & 1.34 & 0.374 & 5.79 & 1.33 & 0.006 & 0.84 & 1.42 & 0.399 \\
\hline B-O & 6.26 & 1.39 & -0.404 & 5.95 & 1.29 & -0.022 & 5.46 & 1.51 & -0.001 & 4.79 & 1.89 & -0.322 & 4.44 & 2.15 & -0.000 & 0.41 & 0.69 & -0.077 \\
\hline B-7 & 5.82 & 1.41 & -0.001 & 5.52 & 1.08 & -0.014 & 5.13 & 1.14 & -0.000 & 5.30 & 1.49 & -0.370 & 4.14 & 1.87 & -0.000 & 0.91 & 1.21 & -0.264 \\
\hline B-14 & 6.45 & 1.44 & 0.487 & 6.59 & 1.44 & 0.254 & 6.54 & 1.88 & 0.184 & 6.04 & 1.64 & 0.015 & 6.05 & 1.82 & 0.062 & 0.79 & 1.30 & 0.172 \\
\hline B-21 & 5.96 & 1.78 & 0.656 & 5.97 & 1.13 & 0.788 & 5.75 & 1.64 & 0.853 & 6.07 & 1.36 & 0.000 & 5.80 & 1.77 & 0.486 & 1.35 & 1.33 & 0.050 \\
\hline
\end{tabular}

P-Values are from the estimated regression coefficients from ANOVA-Partial Least Squares Regression (APLSR). Significant P-Values in BOLD. The Sign dictates weather the correlation is positively or negatively correlated. Values correspond to mean data, \pm corresponds to standard deviation.

\section{Results and Discussion}

\subsection{Sensory Evaluation}

Figure 1 (Treatment X Days) present the ANOVA-Partial Least Squares Regression Plot for each of the treatment samples over time versus the sensory and physiochemical data. Table 1 displays the mean data for sensory (affective and descriptive) evaluations and standard deviations plus the P-values for the regression co-efficients for these data. Table 2 depicts sample coding. In Figure 1 the B-0 and B-7 samples correlate directionally in the upper right hand quadrant of the plot to Toughness (instrumental), DA-0 and T-0 samples correlate directionally in the lower right hand quadrant to cook loss. Samples T-7, T-14, T-21 and DA-7, DA-14 correlate in the lower left hand quadrant of the plot and are directionally correlated to Tenderness, Overall acceptability and Liking of Flavour, whereas B-14 and B-21 and DA-21 were more correlated to Juiciness and Off-flavour. From Table 1 B-0 sample P Values were significantly $(\mathrm{P}<0.05)$ negatively correlated to Liking of Flavour, with B-7 and B-0 samples significantly $(\mathrm{P}<0.05)$ negatively correlated to sensory appearance. Additionally these two samples were significantly $(\mathrm{P}<0.05)$ negatively correlated to Overall Acceptability. Samples DA-0, T-0, B-0 and B-7 were found to be significantly $(\mathrm{P}<0.05)$ negatively correlated to Sensory Tenderness whereas DA-14 and T-21 were significantly $(\mathrm{P}<0.05)$ positively correlated to Tenderness. Samples DA-7, DA-21, $\mathrm{T}-7, \mathrm{~B} 14$ and B21 were significantly $(\mathrm{P}<0.05)$ positively correlated to sensory 
Table 2. Assessment of quality of cooked aged beef products by the assessors for each treatment on each successive test day.

\begin{tabular}{ccccccc}
\hline Code & Treatment & Days & $\begin{array}{c}\text { Unsatisfactory } \\
\text { quality }\end{array}$ & $\begin{array}{c}\text { Good everyday } \\
\text { eating quality }\end{array}$ & $\begin{array}{c}\text { Better than } \\
\text { everyday } \\
\text { eating quality }\end{array}$ & $\begin{array}{c}\text { Premium } \\
\text { quality }\end{array}$ \\
\hline DA-0 & Dry-aged & 0 & 5.00 & 16.00 & 7.00 & 2.00 \\
DA-7 & Dry-aged & 7 & 3.00 & 24.00 & 5.00 & 1.00 \\
DA-14 & Dry-aged & 14 & 1.00 & 18.00 & 9.00 & 5.00 \\
DA-21 & Dry-aged & 21 & 1.00 & 18.00 & 6.00 & 5.00 \\
T-0 & Dry-aged in bag & 0 & 12.00 & 10.00 & 4.00 & 3.00 \\
T-7 & Dry-aged in bag & 7 & 2.00 & 24.00 & 6.00 & 1.00 \\
T-14 & Dry-aged in bag & 14 & 3.00 & 20.00 & 8.00 & 2.00 \\
T-21 & Dry-aged in bag & 21 & 3.00 & 15.00 & 8.00 & 3.00 \\
B-0 & Dry aged with bone & 0 & 7.00 & 15.00 & 3.00 & 5.00 \\
B-7 & Dry aged with bone & 7 & 10.00 & 17.00 & 6.00 & 0.00 \\
B-14 & Dry aged with bone & 14 & 6.00 & 13.00 & 12.00 & 2.00 \\
B-21 & Dry aged with bone & 21 & 6.00 & 15.00 & 8.00 & 1.00 \\
\hline
\end{tabular}

Juiciness. Samples DA-0 and T-0 were significantly $(\mathrm{P}<0.05)$ negatively correlated to Off-flavour. $\mathrm{B}-21$ was not significantly $(\mathrm{P}=0.06)$ positively correlated to Off-Flavour, but was the most correlated of the treatments. Although none of the samples were significantly correlated to Overall Acceptability samples T-21 $(\mathrm{P}<0.072)$ and DA-14 $(\mathrm{P}<0.085)$ were the most correlated. Samples B-0 and $\mathrm{B}-7$ were the most negatively correlated to liking of flavour, but in a real world environment assessors would not encounter these products in a retail or restaurant context. This also applies to Sensory Tenderness where none of the samples over 7 days of aging were considered too tough. This is an interesting finding considering the time and expense incurred in aging meat for 21 days. None of the treatments were correlated to Off-Flavour, but B-21 was the most correlated of the treatments. Perhaps this is due to the presence of bone during the ageing process. DeGeer et al. [9] postulated that leaving the bone on the loin during dry ageing decreased the amount of flavour development, perhaps by limiting the loss of moisture during aging and the resultant "concentration" of flavour components.

As well as determining the significant correlations of products to the sensory terms, as performed above, the significant correlations between products for sensory terms were also determined for each test day and denoted by superscript letters on Table 1. The dry-ageing bag samples (T-21) and the dry aged beef samples (DA-21) scored significantly higher for appearance (Table 1) on D21 compared to bone in aged beef. The dry-ageing bag aged beef scored the highest for appearance of the treatments, but compared to the dry aged beef were not significantly different. No significant differences were also observed for "liking 
of flavour" (Table 1) for any of the treatments on all days of analysis except on D14 where the "liking of flavour" of the bone in aged beef (B-14) was significantly higher than the dry-ageing bag aged beef (T-14), but not significantly different to the dry aged beef (DA-14).

For sensory evaluated juiciness (Table 1 ) the bone-in dry aged beef scored significantly $(\mathrm{P}<0.05)$ higher that the dry-ageing bag and dry aged beef on $\mathrm{D} 7$, D14 and D21 (B-7, B-14, B-21). For sensory evaluated Tenderness (Table 1) dry-ageing bag aged beef (T-7) and the dry aged beef (DA-7) scored significantly $(\mathrm{P}<0.05)$ higher for tenderness compares to bone-in aged beef on day 7 (B-7). All other days were not significantly different between treatments. Off flavour (Table 1) was significantly $(\mathrm{P}<0.05)$ higher for the bone-in aged beef on day 21 (B-21) compared to the dry-ageing bag aged beef (T-21) and the dry aged beef (DA-21). Overall acceptability was significantly $(\mathrm{P}<0.05)$ higher for dry aged beef on Day 21 (DA-21) compared to bone-in aged beef. The dry aged beef and dry-ageing bag aged beef scores for Overall acceptability were not significantly different.

Table 2 also displays the preference of assessors for each treatment on each successive test day using the terms unsatisfactory, good, very good and excellent eating quality to describe the products. For all treatments unsatisfactory and good eating quality decreased from D0 to D21 while very good and excellent eating quality scores increased, which reflects the increase in eating quality of all products during aging. The dry aged beef had the lowest unsatisfactory scores by D21 and the highest good, and excellent eating quality scores. The dry-ageing bag aged products had the next highest excellent eating quality scores. Similar scores were observed for good and very good eating quality for dry-ageing bag and the bone in dry aged beef. The bone in dry aged beef had the highest unsatisfactory scores by $\mathrm{D} 21$.

In summary the results from this study show that that the dry-ageing bag and dry aged beef samples after storage at $2^{\circ} \mathrm{C}$ for 21 days scored higher than the bone in aged beef for appearance. The bone in aged samples were juicier, but had more off-flavour (D21). The dry-aged (DA-14) and dry-aged in bag (T-21) samples were the most correlated to Overall acceptability. These sensory assessor findings are in partial agreement with DeGeer et al. [9], who investigated different dry-aging methods (unpackaged and in a dry-ageing bag), two loin-cut styles (bone-in shell loins and boneless strip loins), and two aging times (21 and 28 days). These authors found that dry aging in a bag produced dry-aged flavour equal to that achieved with traditional dry aging. These data are also in agreement with previous researchers [5], who found the no differences for most quality traits studied for traditional dry aging and aging in a bag which demonstrated the effectiveness of the novel dry-aging method. Some researchers [9] also postulate that leaving the bone on the loin decreased the amount of flavour development, perhaps by limiting the loss of moisture during aging and the resultant "concentration" of flavour components. Differences between the other flavour 
traits were either small or not significant. The results of the current study are also in partial agreement with this finding in that bone in samples (B-21) on D21 had significantly more off-flavour than the other treatments and had significantly less Overall acceptability than the dry aged samples. However the flavour of the dry-ageing bag samples $(\mathrm{T}-14)$ were significantly $(\mathrm{P}<0.05)$ less liked than the bone in samples (B-14) on D14.

Researchers [10] have reported that overall tenderness, flavour, and off flavour intensity were not affected $(P>0.05)$ by any treatment of the beef aging treatments studied (wet-aged, dry-aged and dry-aged in bag). These authors also reported that using a trained sensory panel $(n=6)$ revealed few, if any, differences among dry, vacuum and special bag aging and state that that it is unlikely that assessors could detect any differences. Dikeman et al. [10] used steaks for the sensory evaluation that were frozen at $-40^{\circ} \mathrm{C}$ until just before evaluations by a trained sensory panel. The data from the presented study, on unfrozen beef, clearly disagrees with this statement as assessors detected clear differences between the treatments which were in fact more similar than those used in Dikeman's [10] study. Additionally, the assessors used in the presented study could clearly grade the quality of each of the treatments on each test day (Table 2).

\subsection{Physiochemical Analysis-Texture (Tenderness)}

Figure 1 and Table 3 display the data for beef primal mean shear force values in Newtons with the design variable toughness. As can be seen from this figure the mean texture values decrease for all treatments on successive test days as the treatments move away from the varia be Toughness (instrumental) on the APLSR plot. No significant differences were observed between treatments on Day 0. All treatments were significantly $(\mathrm{P}<0.05)$ negatively correlated to toughness on days 7, 14 and 21 for DA and T and for B14 and B-21. Overall, dry-ageing bag samples displayed the lowest mean shear force values on Days 14 $(\mathrm{T}-14)(19.92 \mathrm{~N})$ and 21 (T-21) (22.6 N). For Day 7 and Day 21 dry-age bag and dry aged samples were significantly $(\mathrm{P}<0.05)$ lower than bone in samples. Destefanis et al. (2008) [62] investigated the relationship between beef assessor tenderness perception and Warner-Bratzler shear force values (WBs). These authors concluded that WBs values $>52.68 \mathrm{~N}$ and $<42.87 \mathrm{~N}$ allow classification of tough and tender beef in a sufficiently reliable way. Therefore from this study we can conclude that the by D21 all samples were very tender, but dry-ageing bag samples were the most tender followed by dry aged samples. These results are in disagreement with the findings of several other researchers [1] [5] [7] [8] [9] who have reported no or minimal differences in WBSF for a variety of aging treatments. DeGeer et al. [9] did not find differences in WBSF values between experimental treatments including shell (bone in) and strip loins (bone less) aged with and without ageing bags. Perhaps this was due to the fact that in DeGeer's study [9] samples were initially frozen then thawed and not presented fresh as in the presented study. Shanks, Wulf, and Maddock [63] showed that 
Table 3. Significance of estimated regression coefficients (ANOVA values) for the relationships of physiochemical data as derived by Jack-knife uncertainty testing for beef steak samples presented with mean data and standard deviations.

\begin{tabular}{|c|c|c|c|c|c|c|c|c|c|c|c|c|c|c|c|c|c|c|c|}
\hline \multirow[t]{2}{*}{ Code } & \multicolumn{3}{|c|}{ L Value } & \multicolumn{3}{|c|}{ a Value } & b Value & \multicolumn{3}{|c|}{ Toughness (N) } & \multicolumn{3}{|c|}{$\mathrm{pH}$} & \multicolumn{3}{|c|}{$\%$ Yield Loss } & \multicolumn{3}{|c|}{$\%$ Cook Loss } \\
\hline & Mean & SD & $\begin{array}{c}P \\
\text { Value }\end{array}$ & Mean & SD & $\begin{array}{c}\mathbf{P} \\
\text { Value }\end{array}$ & Mean SD $\begin{array}{c}P \\
\text { Value }\end{array}$ & Mean & $S D$ & $P$ Value & Mean & $S D$ & $\begin{array}{c}P \\
\text { Value }\end{array}$ & Mean & $\mathrm{SD}$ & $\begin{array}{c}\text { P } \\
\text { Value }\end{array}$ & Mean & $\mathrm{SD}$ & $P$ Value \\
\hline DA-0 & 34.00 & 3.45 & -0.000 & 20.59 & 3.05 & -0.000 & 10.401 & 54 & 13.88 & 0.000 & 5.49 & 0.04 & 446 & $5 \mathrm{NA}$ & NA & NA & NA & NA & NA \\
\hline DA-7 & 39.34 & 1.93 & 0.079 & 27.51 & 1.64 & 0.001 & 15.520 .940 .000 & 24.53 & 6.00 & -0.000 & 5.45 & 0.04 & 0.003 & 3.02 & 0.40 & 0.899 & 26.17 & 2.27 & -0.005 \\
\hline DA-14 & 39.33 & 1.59 & 0.327 & 24.44 & 2.68 & 0.036 & 13.881 .540 .112 & 23.14 & 8.34 & -0.007 & 5.48 & 0.04 & 0.406 & 6.31 & 0.70 & 0.168 & 24.69 & 0.82 & -0.996 \\
\hline DA-21 & 40.98 & 1.65 & 0.250 & 28.23 & 2.51 & 0.008 & 16.501 .450 .010 & 27.73 & 12.46 & -0.020 & 5.52 & 0.01 & 0.014 & 9.32 & 0.91 & 0.010 & 23.40 & 2.62 & -0.008 \\
\hline $\mathrm{T}-0$ & 35.34 & 3.08 & -0.000 & 20.16 & 1.42 & -0.000 & $10.151 .33-0.000$ & 54.03 & 11.00 & 0.000 & 5.49 & 0.02 & -0.969 & 0.00 & 0.00 & NA & NA & NA & NA \\
\hline $\mathrm{T}-7$ & 39.01 & 1.66 & 0.418 & 27.97 & 1.46 & 0.006 & 15.580 .940 .004 & 25.22 & 5.16 & -0.000 & 5.43 & 0.04 & 0.001 & 2.31 & 0.42 & 0.497 & 25.11 & 2.31 & -0.000 \\
\hline $\mathrm{T}-14$ & 39.69 & 3.23 & 0.762 & 24.55 & 1.88 & 0.023 & 13.641 .430 .045 & 19.74 & 5.01 & -0.018 & 5.47 & 0.04 & 0.613 & 4.70 & 0.71 & 0.560 & 25.44 & 2.49 & -0.330 \\
\hline $\mathrm{T}-21$ & 40.59 & 1.51 & 0.369 & 27.39 & 1.69 & 0.000 & 15.701 .020 .000 & 22.57 & 5.16 & -0 & 5.57 & 0.02 & 0.103 & 7.03 & 0.99 & 0.001 & 22.88 & 1.56 & -0.125 \\
\hline $\mathrm{B}-\mathrm{O}$ & 37.53 & 1.13 & -0.001 & 18.65 & 1.48 & -0.000 & $9.921 .15-0.000$ & 58.26 & 21.83 & 0.000 & 5.44 & 0.01 & -0.005 & 0.00 & 0.00 & $\mathrm{NA}$ & NA & NA & NA \\
\hline B-7 & 42.87 & 2.27 & -0.026 & 521.61 & 1.86 & -0.040 & $12.520 .99-0.145$ & 44.61 & 16.97 & 0.000 & 5.45 & 0.03 & -0.081 & 2.24 & 0.07 & -0.026 & 23.65 & 0.55 & 0.788 \\
\hline B-14 & 41.08 & 1.44 & 0.226 & 24.47 & 1.56 & 0.041 & 13.900 .980 .046 & 28.81 & 10.15 & -0.020 & 5.51 & 0.06 & 0.000 & 4.18 & 0.16 & 0.000 & 19.40 & 0.07 & -0.014 \\
\hline B-21 & 40.90 & 3.09 & 0.000 & 27.91 & 3.17 & 0.028 & 15.601 .900 .004 & 30.03 & 10.96 & -0.067 & 5.57 & 0.01 & 0.006 & 6.00 & 0.26 & 0.000 & 20.36 & 1.04 & -0.001 \\
\hline
\end{tabular}

P-Values are from the estimated regression coefficients from ANOVA-Partial Least Squares Regression (APLSR). Significant P-Values in BOLD. The Sign dictates weather the correlation is positively or negatively correlated. Values correspond to mean data, \pm corresponds to standard deviation. 
for aging post 14 days no differences were observed for Lab values for any of the ageing treatments.

\section{4. $\mathrm{pH}$ Changes during Ageing}

Table 3 display the $\mathrm{pH}$ changes for dry aged beef versus dry-ageing bag aged beef versus dry aged bone-in striploin steaks after $0,7,14$ and 21 days at $2^{\circ} \mathrm{C} . \mathrm{pH}$ values were in the range $5.43-5.57$ for all treatments in the study with general increases over the course of the study for all treatments and were not significantly different between any of the treatments for D0, D7 or D14. By D21 dry-aged in bag samples and bon-in samples had the same ph (5.57) which were significantly $(\mathrm{P}<0.05)$ higher than the $\mathrm{pH}$ of the dry-aged samples $(5.52)$. This data is in disagreement with Dikeman et al. [10] who reported the $\mathrm{pH}$ of dry-aged loins was 5.67 , which was higher $(\mathrm{P}<0.01)$ than samples dry-aged in bag aged 5.61, but we are in agreement with Dikeman et al. [10] in that the differences observed though significant are of little practical importance.

\subsection{Yield Loss during Ageing}

Table 3 displays the \% moisture loss of each of the treatments over the 21 days of the study. Samples DA-21, T-21 and B-14 and B-21 were significantly $(\mathrm{P}<$ $0.05)$ correlated to \% Yield loss. The dry aged samples had significantly $(\mathrm{P}<$ 0.05 ) higher moisture losses followed by the dry-age bag and then the bone in aged beef on days 7, 14 and 21. The dry-ageing bag and bone-in samples were not significantly different on days 7 and 14, but the bone-in samples had significantly $(\mathrm{P}<0.05)$ lower losses compared to dry-age bag and dry-aged samples on Day 21 where the dry aged beef lost the most (9.21\%) followed by the dry-aged bag samples $(\sim 6.82 \%)$ and then the bone in dry aged beef $(5.95 \%)$. Statistical analysis of this data displayed that the dry aged samples had significantly $(\mathrm{P}<$ 0.05) higher moisture losses followed by the dry-age bag samples and then the bone in dry aged beef on days 7, 14 and 21. The dry-age bag samples and bone-in samples were not significantly different on days 7 and 14, but the Bone-in samples had significantly $(\mathrm{P}<0.05)$ lower losses compared to dry-age bag samples samples on Day 21 . The dry age samples had significantly higher $(\mathrm{P}$ $<0.05$ ) moisture losses on days 7, 14 and 21 compared to the other treatments. These results are again in partial agreement with DeGeer et al. [9] who found that bone-in shell loins will have about $10 \%-12 \%$ higher yields of dry-aged product than boneless strip loins regardless of the aging method. Dry aging in a bag creates positive effects on yields, with no negative effects on product quality. Trim loss, data not shown, was not significantly different between aged samples using ageing bags or without.

\subsection{Cooking Losses during Ageing}

Cooking losses (Table 3 ) were significantly $(\mathrm{P}<0.05)$ negatively correlated to DA-7, DA-21, T-7, B-14 and B21. Overall cooking losses were less for bone-in 
samples on Days 7, 14 and 21 compared to the dry-ageing bag and dry aged samples. Cooking losses (Table 3 ) were lower on all days and significantly $(\mathrm{P}<$ 0.05) lower for bone-in samples on Days 14 and 21 compared to the dry-ageing bag and dry aged samples which were not significantly different. These results are in agreement with Ahnström et al. [5] who reported similar cooking loss for dry-age bag samples and dry-aged samples. However the present study disagrees with DeGeer et al. (2009) [9] and Dikeman et al. [10] who reported higher cooking losses with dry-age bag samples compared to dry aged samples.

\subsection{Microbiological Changes during Ageing}

Microbiological standards and guidelines give guidance on the types of microorganisms and their number that can be considered acceptable or unacceptable or unsafe in a food product. The following recommended microbiological limits for aerobic plate counts as applied to raw chilled meat: $\mathrm{m}=10^{6}$ or $6 \log (\mathrm{CFU} / \mathrm{g}$ of meat) (acceptable limit) and $\mathrm{M}=10^{7}$ or $7 \mathrm{log}$ (CFU/g of meat) (Unacceptable limit) (ICMSF [64]; European Commision [65]). For this study the limit of acceptability was set to $6 \log$ (CFU/g of meat). Concerning Enterobacteriaceae the recommended microbiological limits are: $\mathrm{M}<2.5 \log (\mathrm{CFU} / \mathrm{g})$ or $\mathrm{M}=2.5 \log$ (CFU/g of meat).

Changes in the aerobic mesophilic counts (AMC), psychrotrophic bacteria and total coliforms on beef primals during storage under different packaging systems at refrigeration temperature $\left(2^{\circ} \mathrm{C}\right)$ are shown in Figures $2(\mathrm{a})-(\mathrm{c})$. The limit of shelf-life stability was set in terms of AMC. Initially, higher microbial counts were obtained in boneless samples than in boneless samples packaged in dry-ageing bag or bone-in carcass samples. The limit of aerobic mesophilic bacteria $\left(10^{6} \mathrm{CFU} / \mathrm{g}\right)$ for chilled meat reported by ICMSF [64] and European Commision [65] was not exceeded in all meat samples on day 0 indicating good quality meat products; however, growth resumed in all samples during storage. The results of the microbiological analysis indicated that the limit of acceptability in terms of aerobic mesophilic bacteria for meat samples stored packaged in dry-ageing bag at refrigeration temperature was reached at days 8 compared to a shelf life of only 7 days for boneless and bone-in samples stored aerobically.

The microbial load on carcasses stored at refrigeration temperature for up to 21 days ranged from $7.3 \times 10^{9}$ to $2.4 \times 10^{10} \mathrm{CFU} \cdot \mathrm{g}^{-1}$ for mesophilic bacteria and from $6.7 \times 10^{9}$ to $9.2 \times 10^{9} \mathrm{CFU} \cdot \mathrm{g}^{-1}$ for psychrotrophic bacteria. The number of mesophillic bacteria was, on average, 1 log cycle higher than psychrotrophic bacteria in bone-in and dry-ageing bag meat samples; however, no significant differences were noticed in the mesophillic and psychrotrophic bacterial load in boneless samples stored aerobically. The growth characteristics of meat spoilage microorganisms depend on the initial microflora, level of contamination, storage time and temperature [66]. As a general rule, meat acquires an offensive odour when the bacterial flora reaches about $10^{7}$ colony forming units $(\mathrm{CFU}) \cdot \mathrm{cm}^{-2}$ or per $\mathrm{g}$ of sample and when numbers have reached about $10^{8} \mathrm{CFU} \cdot \mathrm{cm}^{-2}$ meat becomes slimy. 


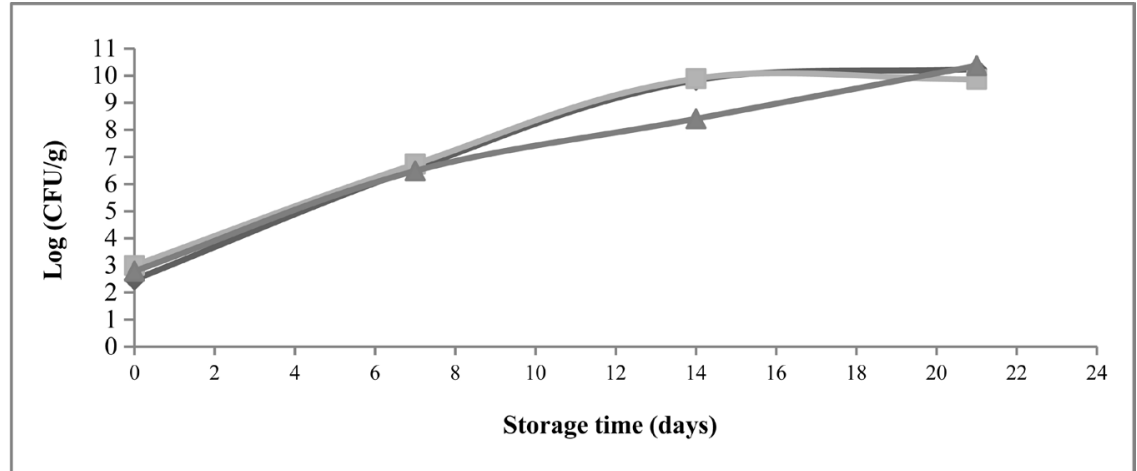

(a)

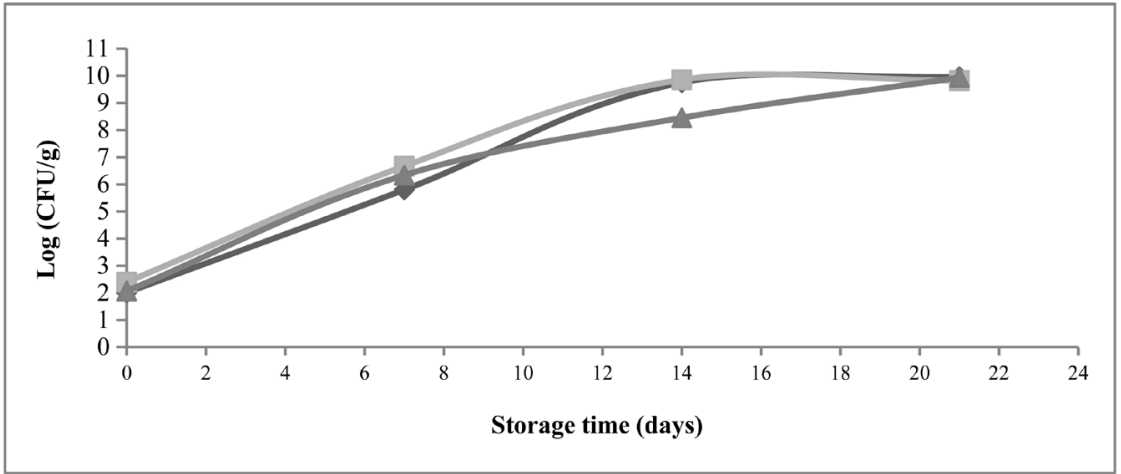

(b)

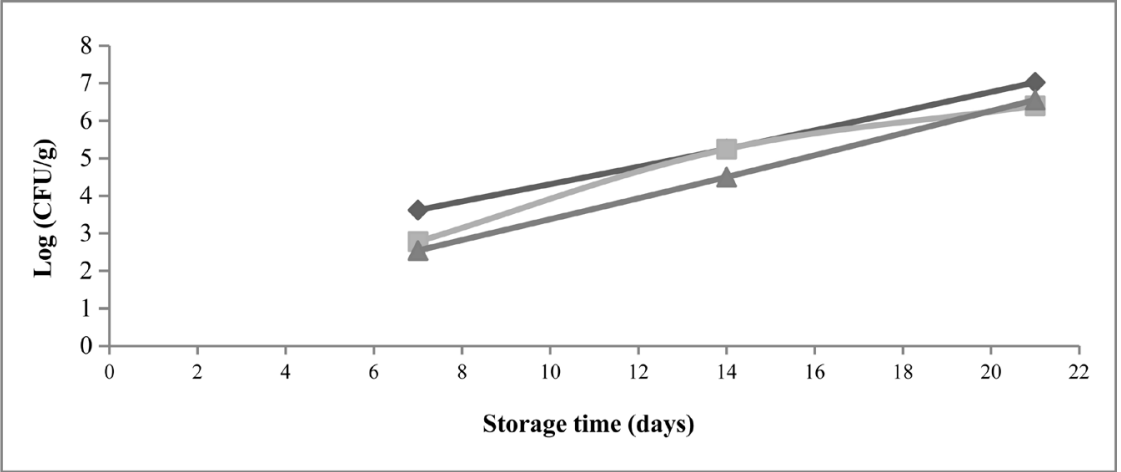

(c)

Figure 2. Changes in the (a) aerobic mesophilic; (b) psychrotrophic and (c) total coliform counts on beef carcasses bone-in $(\boldsymbol{\nabla})$, boneless $(\boldsymbol{\square})$ and dry-ageing bag $(\boldsymbol{\Lambda})$ during storage at refrigeration temperature $\left(4^{\circ} \mathrm{C}\right)$. Values are average of 3 different samples assessed in replicate $(n=6)$.

At day 0 , the total coliform load was below $10 \mathrm{CFU} / \mathrm{g}$ for all samples; however, growth resumed after seven days storage. At day seven, the surface of bone-in carcass sample was higher that the acceptable limit of $2.5 \mathrm{log}$ CFU/g of sample reported by MIG, 2009 [67]. At day 21 the total coliform in all samples were higher than the acceptable limit $2.5 \log$ (CFU/g of meat) and ranged from $2.6 \times$ $10^{6}$ to $1.1 \times 10^{7} \mathrm{CFU} \cdot \mathrm{g}^{-1}$, bone-in samples having the highest total coliform count. Throughout the storage E. coli was not detected in all meat samples. To obtain a good shelf life of the matured beef carcasses it is necessary that the ini- 
tial quality of the steak is high, because packaging can only maintain the existing quality of the meat.

At the end of storage, microbiological analysis of the internal part of the carcass after sectioning was carried out. The interior of fresh meat from healthy animals is almost free of bacteria and other microorganisms [67]. All samples had AMC below the acceptability level of $10^{6} \mathrm{CFU} / \mathrm{g}$ of meat. The mesophillic bacterial load was $6.0 \times 10^{3}, 3.8 \times 10^{4}$ and $3.1 \times 10^{4} \mathrm{CFU} / \mathrm{g}$ of meat for bone-in, boneless and dry-ageing bag samples, respectively. The relatively higher content on the mesophillic bacteria was probably due to cross contamination from the surface of the carcass when the sterile knife went through the flesh for portioning. Therefore, to avoid cross-contamination it is recommended that the surface of the carcass is removed before sectioning or portioning. The outer surface of meat samples was trimmed prior to sensory analysis.

From the microbiological point of view, the lowest counts for (Figure 2(a)) mesophilic; (Figure 2(b)) psychrotrophic and (Figure 2(c)) total coliform counts were found for dry-aged bag samples on D14 (T-14). The other treatments did not differ on days 0,7 and 21 . These results are general agreement with DeGeer et al. [9] who found that, bag dry aging beef had no significant differences in E. coli/coliforms and lactic acid bacteria microbial growth than that of traditional dry aging after 21 days.

\section{Conclusion}

The results from this study show that that the dry-ageing bag and dry aged beef samples after storage at $2^{\circ} \mathrm{C}$ for 21 days generally scored higher than the bone in aged beef for Appearance. The bone in aged samples were juicier, but had more off-flavour. The dry-aged (DA-14) and dry-aged bag samples (T-21) scored higher than the bone-in aged samples for overall acceptability and thus were liked more. For Day 7 and Day 21 dry-ageing bag and dry aged samples had significantly $(\mathrm{P}<0.05)$ lower shear force values than bone in samples. Overall dry-ageing bag samples displayed the lowest mean shear force values on Days 14 and 21 and thus were the most tender treatments. The dry aged samples had higher moisture losses followed by the dry-ageing bag aged and then the bone-in dry aged beef on days 7, 14 and 21. Thus, dry-ageing bag aged samples were highly acceptable from a assessor perspective and fit the profile of aged beef with reduced moisture and losses and greater tenderness. However, Trim losses were not significantly different between dry aged samples and dry-ageing bag samples after 21 days. From the microbiological point of view, there was no optimal packaging system for maturing beef loins for 3 weeks although dry-aged bag (T-14) samples had the lowest TVC counts on Day 14. The sensory methods utilised allowed samples to be assessed hedonically and descriptively in real time without the necessity to freeze samples and without reverse storage design.

\section{Acknowledgements}

The research reported in this manuscript was funded by University College Cork 
with the assistance of materials supplied by Dawn meats (Waterford, Ireland) and TUB-EX ApS, Denmark.

\section{Conflicts of Interest}

The authors declare that there is no conflict of interests regarding the publication of this paper. All procedures followed were in accordance with the ethical standards of the responsible committee on human experimentation (institutional and national) and with the Helsinki declaration of 1975, as revised in 2008 (5). No laboratory animals were used in this study.

\section{References}

[1] Smith, R.D., Nicholson, K.L., Nicholson, J.D.W., Harris, K.B., Miller, R.K., Griffin, D.B. and Savell, J.W. (2008) Dry versus Wet Aging of Beef: Retail Cutting Yields and Assessor Palatability Evaluations of Steaks from US Choice and US Select Short loins. Meat Science, 79, 631-639. https://doi.org/10.1016/j.meatsci.2007.10.028

[2] Campbell, R.E., Hunt, M.C., Levis, P. and Chambers IV, E. (2001) Dry Aging Effect on Palatability of Beef Longissimus Muscle. Journal of Food Science, 66, 196-199. https://doi.org/10.1111/j.1365-2621.2001.tb11315.x

[3] Parrish Jr., F.C., Boles, J.A., Rust, R.E. and Olson, D.G. (1991) Dry and Wet Aging Effects on Palatability Attributes of Beef Loin and Rib Steaks from Three Quality Grades. Journal of Food Science, 56, 601-603. https://doi.org/10.1111/j.1365-2621.1991.tb05338.x

[4] Warren, K.E. and Kastner, C.L. (1992) A Comparison of Dry-Aged and Vacuum-Aged Beef Strip Loins. Journal of Muscle Foods, 3, 151-157. https://doi.org/10.1111/j.1745-4573.1992.tb00471.x

[5] Ahnström, M.L, Seyfert, M., Hunt, M.C. and Johnson, D.E. (2006) Dry Aging of Beef in a Bag Highly Permeable to Water Vapour. Meat Science, 73, 674-679. https://doi.org/10.1016/j.meatsci.2006.03.006

[6] Miller, M.F., Kerth, C.R., Wise, J.W., Lansdell, J.L., Stowell, J.E. and Ramsey, C.B. (1997) Slaughter Plant Location, USDA Quality Grade, External Fat Thickness, and Aging Time Effects on Sensory Characteristics of Beef Loin Strip Steak. Journal of Animal Science, 75, 662-667. https://doi.org/10.2527/1997.753662x

[7] Laster, M.A., Smith, R.D., Nicholson, K.L., Nicholson, J.D.W., Miller, R.K., Griffin, D.B., Harris, K.B. and Savell, J.W. (2008) Dry versus Wet Aging of Beef: Retail Cutting Yields and Assessor Sensory Attribute Evaluations of Steaks from Ribeyes, Strip Loins, and Top Sirloins from Two Quality Grade Groups. Meat Science, 80, 795-804. https://doi.org/10.1016/j.meatsci.2008.03.024

[8] Sitz, B.M., Calkins, C.R., Feuz, D.M., Umberger, W.J. and Eskridge, K.M. (2006) Assessor Sensory Acceptance and Value of Wet-Aged and Dry-Aged Beef Steaks. Journal of Animal Science, 84, 1221-1226. https://doi.org/10.2527/2006.8451221x

[9] DeGeer, S.L., Hunt, M.C., Bratcher, C.L., Crozier-Dodson, B.A., Johnson, D.E. and Stika, J.F. (2009) Effects of Dry Aging of Bone-In and Boneless Strip Loins Using Two Aging Processes for Two Aging Times. Meat Science, 83, 768-774. https://doi.org/10.1016/j.meatsci.2009.08.017

[10] Dikeman, M.E., Obuz, E., Gök, V., Akkaya, L. and Stroda, S. (2013) Effects of Dry, Vacuum, and Special Bag Aging; USDA Quality Grade; and End-Point Temperature on Yields and Eating Quality of Beef Longissimus lumborum Steaks. Meat Science, 
94, 228-233. https://doi.org/10.1016/j.meatsci.2013.02.002

[11] Fellendorf, S., O’Sullivan, M.G. and Kerry J.P. (2015) Impact of Varying Salt and Fat Levels on the Physiochemical Properties and Sensory Quality of White Pudding Sausages. Meat Science, 103, 75-82. https://doi.org/10.1016/j.meatsci.2014.12.010

[12] Fellendorf, S., O’Sullivan, M.G. and Kerry J.P. (2017) Effect of Different Salt and Fat Levels on the Physicochemical Properties and Sensory Quality of Black Pudding. Food Science \& Nutrition, 5, 273-284. https://doi.org/10.1002/fsn3.390

[13] Fellendorf, S., O’Sullivan, M.G. and Kerry J.P. (2016) Effect of Using Replacers on the Physicochemical Properties and Sensory Quality of Low Salt and Low Fat White Puddings. European Food Research and Technology, 242, 2105-2118. https://doi.org/10.1007/s00217-016-2707-Z

[14] Fellendorf, S., O’Sullivan, M.G. and Kerry J.P. (2016) Impact of Using Replacers on the Physicochemical Properties and Sensory Quality of Reduced Salt and Fat Black Pudding. Meat Science, 113, 17-25. https://doi.org/10.1016/j.meatsci.2015.11.006

[15] Fellendorf, S., Kerry, J.P., Hamill, R.H. and O'Sullivan, M.G (2018) Impact on the Physicochemical and Sensory Properties of Salt Reduced Corned Beef Formulated with and without the Use of Salt Replacers. LWT-Food Science and Technology, 92, 584-592. https://doi.org/10.1016/j.lwt.2018.03.001

[16] Delgado-Pando, G., Allen, P., Fischer, E., O’Sullivan, M., Kerry, J. and Hamill, R.M. (2018) Salt Content and Minimum Acceptable Levels in Whole-Muscle Cured Meat Products. Meat Science, 139, 179-186. https://doi.org/10.1016/j.meatsci.2018.01.025

[17] Guerrero, P., O'Sullivan, M.G., Kerry, J.P. and de la Caba, K. (2015) Application of Soy Protein Coatings and Their Effect on the Quality and Shelf-Life Stability of Beef Patties. Royal Society of Chemistry Advances, 5, 8182-8189.

[18] Kilcawley, K.N., Faulkner, H., Clarke, H.J., O’Sullivan, M.G. and Kerry, J.P. (2018) Factors Influencing the Flavor of Bovine Milk and Cheese from Grass Based versus Non-Grass Based Milk Production Systems. Foods, 7, 37. https://doi.org/10.3390/foods7030037

[19] Faulkner, H., O’Sullivan, M.G., Kerry, J.P. and Kilcawley, K.N. (2017) Impact of Different Forage Types on the Volatile and Sensory Properties of Bovine Milk. Journal of Dairy Science, 101, 1034-1047. https://doi.org/10.3168/jds.2017-13141

[20] Bertuzzi, A.S., Kilcawley, K.N., Sheehan, J.J., O’Sullivan, M.G., Kennedy, D., McSweeney, P.L.H. and Rea, M.C. (2017) Use of Smear Bacteria and Yeasts to Modify Flavour and Appearance of Cheddar Cheese. International Dairy Journal, 72, 44-54. https://doi.org/10.1016/j.idairyj.2017.04.001

[21] Cavanagh, D., Kilcawley, K.N., O’Sullivan, M.G., Fitzgerald, G.F. and McAuliffe, O. (2014) Assessment of Wild Non-Dairy Lactococcal Strains for Flavour Diversification in a Mini Gouda Type Cheese Model. Food Research International, 62, 432-440. https://doi.org/10.1016/j.foodres.2014.03.043

[22] Gethins, L., Rea, M., Stanton, C., Ross, R.P., Kilcawley, K., O’Sullivan, M.G., Crotty, S. and Morrissey, J. (2016) Acquisition of the Yeast Kluyveromyces marxianus from Unpasteurised Milk by a Kefir Grain Enhances Kefir Quality. FEMS Microbiology Letters, 363, fnw165. https://doi.org/10.1093/femsle/fnw165

[23] Henneberry, S., O’Sullivan, M.G., Kilcawley, K.N., Kelly, P.M., Wilkinson, M.G. and Guinee, T.P. (2016) Sensory Quality of Unheated and Heated Mozzarella-Style Cheeses with Different Fat, Salt and Calcium Levels. International Journal of Dairy Science, 69, 38-50.

[24] Hickey, C.D., O’Sullivan, M.G., Davis, J., Scholz, D., Kilcawley, K.N., Wilkinson, 
M.G. and Sheehan, J.J. (2018) The Effect of Buttermilk or Buttermilk Powder Addition on Functionality, Textural, Sensory and Volatile Characteristics of Cheddar-Style Cheese. Food Research International, 103, 468-477.

https://doi.org/10.1016/j.foodres.2017.09.081

[25] O’Callaghan, T., Mannion, D.T., Hennessy, D., McAuliffe, S., O’Sullivan, M.G., Leeuwebdaal, N., Beresford, T.P., Dillon, P., Kilcawley, K.N., Sheehan, D.J., Ross, P. and Stanton, C. (2017) Effect of Pasture versus Indoor Feeding Systems on Quality Characteristics, Nutritional Composition, and Sensory and Volatile Properties of Full-Fat Cheddar Cheese. Journal of Dairy Science, 100, 6053-6073.

https://doi.org/10.3168/jds.2016-12508

[26] O’Callaghan, T., Faulkner, H., McAuliffe, S., O’Sullivan, M.G., Hennessy, D., Dillon, P., Kilcawley, K.N., Stanton, C. and Ross, P. (2016) Quality Characteristics, Chemical Composition, and Sensory Properties of Butter from Cows on Pasture versus Indoor Feeding Systems. Journal of Dairy Science, 99, 9441-9460. https://doi.org/10.3168/jds.2016-11271

[27] Walsh, A., Crispie, F., Kilcawley, K.N., O’Sullivan, O., O’Sullivan, M.G., Claesson, M. and Cotter, P. (2016) Microbial Succession and Flavour Production in the Fermented Dairy Beverage Kefir. mSystems, 1, e00052-16. https://doi.org/10.1128/mSystems.00052-16

[28] Yarlagadda, A., Wilkinson, M.G., Ryan, S., Doolan, A.I., O’Sullivan, M.G. and Kilcawley, K.N. (2014) Utilisation of a Cell Free Extract of Lactic Acid Bacteria Entrapped in Yeast to Enhance Flavour Development in Cheddar Cheese. International Journal of Dairy Science Technology, 67, 21-30. https://doi.org/10.1111/1471-0307.12099

[29] Yarlagadda, A., Wilkinson, O’Sullivan, M.G. and Kilcawley, K.N. (2014) Utilisation of Microfluidisation to Enhance Enzymatic and Metabolic Potential of Lactococcal Strains as Adjuncts in Gouda Type Cheese. International Dairy Journal, 38, 124-132. https://doi.org/10.1016/j.idairyj.2014.01.007

[30] Hempel, A., O’Sullivan, M.G., Papkovsky, D. and Kerry, J.P. (2013) Non-Destructive and Continuous Monitoring of Oxygen Levels in Modified Atmosphere Packaged Ready-to-Eat Mixed Salad Products Using Optical Oxygen Sensors. Journal of Food Science, 78, S1057-S1062. https://doi.org/10.1111/1750-3841.12164

[31] Hempel, A., O’Sullivan, M.G., Papkovsky, D. and Kerry, J.P. (2013c) Assessment and Use of Optical Oxygen Sensors as Tools to Assist in Optimal Product Component Selection for the Development of Packs of Ready-to-Eat Mixed Salads and for the Non-Destructive Monitoring of In-Pack Oxygen Levels Using Chilled Storage. Foods, 2, 213-224. https://doi.org/10.3390/foods2020213

[32] Richardson, A.M., Tyuftin, A., Kilcawley, K.N., Gallagher, E., O’Sullivan, M.G. and Kerry, J.P. (2018) Impact of Sugar Particle Size Manipulation on the Physical and Sensory Properties of Chocolate Brownies. Food Science and Technology, 95, 51-57. https://doi.org/10.1016/j.lwt.2018.04.038

[33] Hempel, A., O’Sullivan, M.G., Papkovsky, D. and Kerry, J.P. (2013) Use of Smart Packaging Technologies for Monitoring and Extending the Shelf-Life Quality of Modified Atmosphere Packaged (MAP) Bread: Application of Intelligent Oxygen Sensors and Active Ethanol Emitters. European Food Research and Technology, 237, 117-124. https://doi.org/10.1007/s00217-013-1968-Z

[34] Hempel, A., O’Sullivan, M.G., Papkovsky, D. and Kerry, J.P. (2013) Use of Optical Oxygen Sensors to Monitor Residual Oxygen in Pre- and Post-Pasteurised Bottled Beer and Its Effect on Sensory Attributes and Product Acceptability during Simulated Commercial Storage. Food Science and Technology, 50, 226-231. 
https://doi.org/10.1016/j.lwt.2012.05.026

[35] Stokes, C., O’Sullivan, M.G. and Kerry, J.P. (2016) Assessment of Black Coffee Temperature Profiles Consumed from Paper-Based Cups and Effect on Affective and Descriptive Product Sensory Attributes. International Journal of Food Science and Technology, 51, 2041-2048. https://doi.org/10.1111/ijfs.13176

[36] Stokes, C., O’Sullivan, M.G. and Kerry, J.P. (2017) Hedonic and Descriptive Sensory Evaluation for Development of Novel Instant and Fresh Coffee Products. European Food Research and Technology, 243, 331-340. https://doi.org/10.1007/s00217-016-2747-4

[37] Stokes, C., O’Sullivan, M.G. and Kerry, J.P. (2018) Rapid Descriptive Consumer Analysis Using Simultaneous and Monadic Sample Presentation for Coffee. Food and Nutrition Sciences, 9, 63-76. https://doi.org/10.4236/fns.2018.92005

[38] O’Sullivan, M.G. (2017) CH3. Sensory Affective (Hedonic) Testing. In: A Handbook for Sensory and Consumer Driven New Product Development. Innovative Technologies for the Food and Beverage Industry, Woodhead Publishing, Sawston, 39-57. https://doi.org/10.1016/B978-0-08-100352-7.00003-8

[39] O’Sullivan, M.G., Le Floch, S. and Kerry, J.P. (2015) Resting of MAP (Modified Atmosphere Packed) Beef Steaks Prior to Cooking and Effects on Consumer Quality. Meat Science, 101, 13-18. https://doi.org/10.1016/j.meatsci.2014.10.030

[40] O’Sullivan, M.G., Cruz, M. and Kerry, J.P. (2011) Evaluation of Carbon Dioxide Flavour Taint in Modified Atmosphere Packed Beef Steaks. Food Science and Technology, 44, 2193-2198. https://doi.org/10.1016/j.lwt.2011.06.010

[41] Tobin, B.D., O'Sullivan, M.G., Hamill, R.M. and Kerry, J.P. (2012a) Effect of Varying Salt and Fat Levels on the Sensory Quality of Beef Patties. Meat Science, 4, 460-465. https://doi.org/10.1016/j.meatsci.2012.02.032

[42] Tobin, B.D., O’Sullivan, M.G., Hamill, R.M. and Kerry, J.P. (2012b) Effect of Varying Salt and Fat Levels on the Sensory and Physiochemical Quality of Frankfurters. Meat Science, 92, 659-666. https://doi.org/10.1016/j.meatsci.2012.06.017

[43] Tobin, B.D., O’Sullivan, M.G., Hamill, R.M. and Kerry, J.P. (2013) The Impact of Salt and Fat Level Variation on the Physiochemical Properties and Sensory Quality of Pork Breakfast Sausages. Meat Science, 93, 145-152. https://doi.org/10.1016/j.meatsci.2012.08.008

[44] Tobin, B.D., O’Sullivan, M.G., Hamill, R.M. and Kerry, J.P. (2013) European Consumer Attitudes on the Associated Health Benefits of Neutraceutical-Containing Processed Meats Using Co-Enzyme Q10 as a Sample Functional Ingredient. Meat Science, 97, 207-213. https://doi.org/10.1016/j.meatsci.2014.01.010

[45] Tobin, B.D., O’Sullivan, M.G., Hamill, R.M. and Kerry, J.P. (2014) Effect of Cooking and in Vitro Digestion on Co-Enzyme Q10 in Processed Meat Products Fortified with Co-Enzyme Q10. Food Chemistry, 150, 187-192.

https://doi.org/10.1016/j.foodchem.2013.10.138

[46] Traynor, M., Burke, R., O’Sullivan, M.G., Hannon, J. and Barry-Ryan, C. (2013) Sensory and Chemical Interactions of Food Pairings (Basmati Rice, Bacon and Extra Virgin Olive Oil) with Banana. Food Research International, 54, 569-577. https://doi.org/10.1016/j.foodres.2013.07.050

[47] O’Sullivan, M.G. (2017) CH4. Rapid Sensory Profiling Methods. In: A Handbook for Sensory and Consumer Driven New Product Development. Innovative Technologies for the Food and Beverage Industry, Woodhead Publishing, Sawston, 59-82. https://doi.org/10.1016/B978-0-08-100352-7.00004-X

[48] O’Sullivan, M.G. (2017) CH11. Sensory Properties Affecting Meat and Poultry 
Quality. In: A Handbook for Sensory and Consumer Driven New Product Development. Innovative Technologies for the Food and Beverage Industry, Woodhead Publishing, Sawston, 225-257. https://doi.org/10.1016/B978-0-08-100352-7.00011-7

[49] O’Sullivan, M.G. (2017) CH12. Sensory Properties of Dairy Products. In: A Handbook for Sensory and Consumer Driven New Product Development. Innovative Technologies for the Food and Beverage Industry, Woodhead Publishing, Sawston, 259-280. https://doi.org/10.1016/B978-0-08-100352-7.00012-9

[50] O’Sullivan, M.G. (2017) CH13. Sensory Properties of Beverage Products. In: $A$ Handbook for Sensory and Consumer Driven New Product Development. Innovative Technologies for the Food and Beverage Industry, Woodhead Publishing, Sawston, 281-304. https://doi.org/10.1016/B978-0-08-100352-7.00013-0

[51] O’Sullivan, M.G. (2017) CH14. Sensory Properties of Bakery and Confectionary Products. In: A Handbook for Sensory and Consumer Driven New Product Development. Innovative Technologies for the Food and Beverage Industry, Woodhead Publishing, Sawston, 305-324. https://doi.org/10.1016/B978-0-08-100352-7.00014-2

[52] O’Sullivan, M.G. (2017) CH5. Multivariate Data Analysis. In: A Handbook for Sensory and Consumer Driven New Product Development. Innovative Technologies for the Food and Beverage Industry, Woodhead Publishing, Sawston, 83-99. https://doi.org/10.1016/B978-0-08-100352-7.00005-1

[53] Lawless, H.T. and Heymann, H. (2010) Sensory Evaluation of Food. Principles and Practices. 2nd Edition, Springer, New York. https://doi.org/10.1007/978-1-4419-6488-5

[54] Byrne, D.V., O’Sullivan, M.G., Bredie, W.L.P. and Martens, M. (2002) Descriptive Sensory Profiling and Physical/Chemical Analyses of Warmed-Over Flavour in Meat Patties from Carriers and Non-Carriers of the RN(-) Allele. Meat Science, 63, 211-224. https://doi.org/10.1016/S0309-1740(02)00072-4

[55] Stone, H. and Sidel, J.L. (2004) Affective Testing. In: Stone, H. and Sidel, J., Eds., Sensory Evaluation Practices, 3rd Edition, Elsevier Academic Press, Cambridge, 247-277.

[56] Stone, H., Bleibaum, R.N. and Thomas, H.A. (2012) Chapter 7; Affective Testing. In: Stone, H., Bleibaum, R.N. and Thomas, H.A., Eds., Sensory Evaluation Practices, 4th Edition, Elsevier Academic Press, Cambridge, 306-309.

https://doi.org/10.1016/B978-0-12-382086-0.00007-8

[57] Richter, V., Almeida, T., Prudencio, S. and Benassi, M. (2010) Proposing a Ranking Descriptive Sensory Method. Food Quality and Preference, 21, 611-620.

https://doi.org/10.1016/j.foodqual.2010.03.011

[58] Stone, H., Bleibaum, R.N. and Thomas, H.A. (2012) Chapter 4; Test Strategy and Design of Experiments. In: Stone, H., Bleibaum, R.N. and Thomas, H.A., Eds., Sensory Evaluation Practices, 4th Edition, Elsevier Academic Press, Cambridge, 135. https://doi.org/10.1016/B978-0-12-382086-0.00004-2

[59] ISO (1988) International Standard 8589. Sensory Analysis. General Guidance for the Design of Test Rooms Ref. No. ISO 8589:1988 (E). International Organization for Standardization, Genève.

[60] Martens, H. and Martens, M. (1999) Validation of PLS Regression Models in Sensory Science by Extended Cross-Validation. In: Tenenhause, M. and Monineau, A., Eds., Les Methodes PLS, Cisia-Ceresta, Montreuil, 149-182.

[61] Martens, H. and Martens, M. (2001) In Multivariate Analysis of Quality: An Introduction. John Wiley and Sons, Chichester, 139-145.

[62] Destefanis, G., Brugiapaglia, A., Barge, M.T. and Dal Molin, E. (2008) Relationship 
between Beef Assessor Tenderness Perception and Warner-Bratzler Shear Force. Meat Science, 78, 153-156. https://doi.org/10.1016/j.meatsci.2007.05.031

[63] Shanks, B.C., Wulf, D.M. and Maddock, R.J. (2002) Technical Note: The Effect of Freezing on Warner-Bratzler Shear Force Values of Beef Longissimus Steaks across Several Postmortem Aging Periods. Journal of Animal Science, 80, 2122-2125.

[64] ICMSF International Commission on Microbiological Specifications of Food (1986) Microorganisms in Foods 2. Sampling for Microbiological Analysis: Principles and Specific Applications. 2nd Edition.

[65] European Commission (2007) Commission Regulation (EC) 1447/2007 of 5 December 2007 on Amending Regulation (EC) 2073/2005 on Microbiological Criteria on Foodstuffs. Official Journal of the European Union, L322/12-L322/29.

[66] Kotula, K.L. and Kotula, A.W. (2000) Fresh Read Meats. In: Lund, B.M., Baird-Parker, T.C. and Gould, G.W., Eds., The Microbiological Safety and Quality of Food, Aspen Publishers, Inc., Frederick, 361-368.

[67] MIG (Meat Industry Guide) (2009) Food Hygiene and Other Regulations for the UK Meat Industry. http://www.food.gov.uk/foodindustry/meat/guidehygienemeat 